\title{
Lola Hoffmann: Terapeuta Jungiana (1904-1988) Lola Hoffmann: Therapeutist Jungiana (1904-1988)
}

Enrique Escobar M.1

The changes of course of their life helped her to develop the ability and the skill so that guided by the work of Jung it reached in the second half of their existence their definitive vocation. As that she underwent an herself analysis interpreting their own dreams to develop their individuation. More and more enriched it was under conditions of helping their patients who their charismatic condition and their prestige like wise woman appreciated.

Key words: Lola Hoffmann, Jungiano Group, Dreams.

Rev Chil Neuro-Psiquiat 2008; 46 (1): 63-65

\section{Antecedentes biográficos}

$\mathrm{L}$ a influencia de Lola Hoffmann en el campo de la psicoterapia es probablemente desconocida para las generaciones actuales de profesionales de salud mental. La naturaleza de su contribución, está muy entrelazada con su propio desarrollo personal por lo que nosotros destacaremos algunos eventos biográficos. Helena Jacovy -Lola Hoffmann- nació en Riga, capital de la Letonia actual el 19 de marzo de 1904. Fue la segunda de tres niños que tuvo el matrimonio de Sigfrid Jacoby y Selma Jacoby, primos hermanos. Su padre era abogado de prestigio y su madre una mujer, independiente y autónoma hecho poco frecuente en esa época. El buen pasar de los Jacoby cambió abruptamente con la Primera Guerra Mundial. En 1919 en plena invasión bolchevique los Jacovy pudieron dejar su ciudad y establecerse en Alemania en Freiburgo. En esa ciu- dad Helena estudió Medicina, en desacuerdo con el deseo de sus padres.

Se graduó en 1928 y trabajó en investigación básica hasta que conoció a un becado chileno el Dr. Franz Hoffmann, con quién se casó. El matrimonio tuvo dos niños Adriana y Francisco que vivieron acompañados por sus tíos maternos y primos en la misma casa.

Instalados los Hoffmann en la Cátedra de Fisiología de la Universidad de Chile, trabajaron como académico contratado Franz y su esposa como ayudante ad-honorem, condición que se mantuvo los veinticinco años que dedicó a la investigación. De hecho a los cuarenta cinco años empezó a percibir una inseguridad insidiosa y molesta que derivó en un desapego de su vocación. ¿Como explicar ese cambio a esa altura de su vida? Permitamos que ella se explique "Mi trabajo en el Instituto de Fisiología no fue remunerado y la idea que Franz se muriera era tremen-

Recibido: 12 de diciembre de 2007

Aceptado: 15 de marzo de 2008

1 Instituto Psiquiátrico Dr. José Horwitz B. 


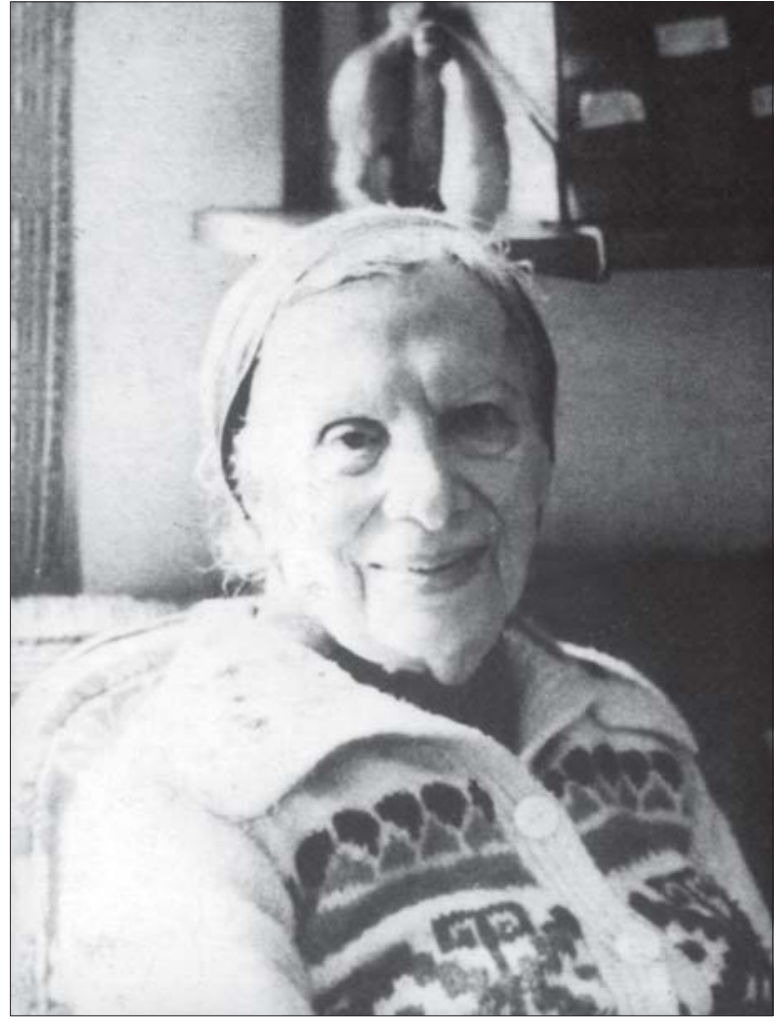

da para mí". "Yo empecé a cuestionar mi dependencia afectiva, y económica de Franz que contrastaba con mi independencia abandonada y productiva en mi juventud".

Muy perturbada por su situación, decidió antes que nada revalidar su título de médico-cirujano, sin ningún proyecto definido. Sin embargo, a sus manos llegó un libro de la teoría de C.G. Jung escrito por Yolanda Jacovy, alumna del investigador. Su lectura la impactó de tal manera que localizó a la autora en Munich quien después de escucharla le interpretó un sueño experimentado antes de dejar la Fisiología. En el sueño se vio haciendo una preparación habitual en que abría el tórax a un perro, pero en este caso del interior del animal aparecía la Srta. Engel, la secretaria del Instituto, sintió tanto miedo pues pensaba que la había matado, que bruscamente despertó. La interpretación de la Dra. Jacoby era que ella estaba matando su propio ángel (engel en alemán es ángel) al trabajar en el laboratorio. La estimuló para seguir su propia intuición para que se consagrara a la psiquiatría. Se consiguió en 1953 una cargo ad honorem en la Clínica Psiquiátrica dirigida por el Dr. Ignacio Matte donde permaneció cinco años y luego viajó a Europa para estudiar con Ernst. Kretschmer y Eugen Bleuler, conociendo también al ya anciano Jung.

A lo expuesto ya es hora de referir su encuentro con el escultor Tótila Albert, con quién estableció una relación sentimental que duró hasta la muerte del escultor. De hecho la relación con el escultor impactó en otro cambio de dirección que dio a su vida como lo declara ella misma: "era el encuentro tan importante que de repente con un soplo cambió toda mi vida... Un tiempo extremadamente feliz, y muy triste también, porque pasaba entre la culpa y el amor"... "Yo lo acompañé durante diecisiete años, hasta su muerte, en una relación en que los dos continuamos manteniendo nuestra propia vida familiar".

Gracias a Tótila, Lola afirma que ella recibió una energía que la ayudó en su individuación.. Lola continuó apoyando a sus pacientes y progresando hasta los últimos días de su vida.

\section{Su trabajo}

Lola Hoffmann fue pionera del movimiento Jungiano en Chile en una época en que el psicoanálisis Freudiano tenía el respaldo académico. Sin embargo, persistió en divulgar la obra de Jung organizando grupos de estudio y talleres de sueños, germen de la Fundación C G Jung.

Jung seguidor en un principio de $S$ Freud se marchó pronto del psicoanálisis pues su visión del mecanismo mental en la aparición de la Neurosis era diferente. Jung basó su terapia mediante el proceso de la individuación que eleva a un ser humano a la unificación de la personalidad. Para eso recurre a varios procedimiento para analizar al inconsciente siendo el principal la interpretación de los sueños.

Lola Hoffmann siguiendo a Jung se dedicó al principio a analizar sus propios sueños desarrollando la aptitud y la habilidad para trabajar con 
sus pacientes. Su conocimiento de la simbología y la cultura greco romana, judeo cristiana y de los países orientales le permitió adquirir una rica noción de la mitología, las leyendas y el folklore. Durante treinta ocho años registró tanto sus propios sueños como los sueños de sus pacientes. Su técnica incluía estimular al soñante, tal como señala Jung, a la amplificación, consistente en examinar todas las connotaciones posibles del contenido del sueño -incluyendo lo irracional y lo fantástico- con referencia a su vida cotidiana y biográfica. Confirmó -como decía su maestroque más que un sueño individual es una serie de sueños lo que permiten estudiar su significado. Igualmente ella observó las coincidencias que se encuentran entre los sueños de dormidores dife- rentes: "El alma en el mundo entero es la misma. El fondo del alma sabe que no es mortal que la vida es como un paso por la materia y que si el hombre se permite guiar, escuchar, obedecer y actuar ha completado una misión".

Cuando progresó en su propia individuación estuvo mejor preparada para aliviar el sufrimiento de sus pacientes. De la misma manera creció su condición carismática y su prestigio como la mujer sabia, objetivo terapéutico último: la sabiduría, que postulaba Jung. En sus últimos años buscó nuevos procedimientos para abrir la percepción a través de fuentes orientales -tradujo al castellano el libro de los cambios el I Ching- y de fuentes occidentales como el uso controlado del LSD en boga en los sesenta.

\section{Resumen \\ Los cambios del curso de su vida le permitieron desarrollar la habilidad y la destreza para que guiada por el trabajo de Jung alcanzara en la segunda mitad de su existencia su vocación definitiva. Como aquel procedió a un autoanálisis mediante la interpretación de sus propios sueños para desarrollar su individuación. Cada vez más enriquecida espiritualmente pudo ayudar a sus pacientes quienes apreciaron su condición carismática y su prestigio como la mujer sabia.}

Palabras clave: Lola Hoffmann, Escuela Jungiana, Sueños.

\section{Referencias}

1. Calderón L. Mi Abuela Lola Hoffmann. 20 edición Cuatro Vientos. Editorial Santiago, Chile 1997.

2. Ellenberger $\mathrm{H}$. El Descubrimiento del Inconsciente Historia y Evolución de la Psiquiatría Dinámica. Editorial Gredos Madrid, 1976.

3. Jung C G. Arquetipos e Inconsciente Colectivo.
Paidos. Buenos Aires, 1981.

4. Reyes W, Julia X. Bienaventurado el que no se escandalice de mí. Notas Psicobiográficas de Lola Hoffmann. Terapia Psicológica 2001; Vol 19 (36): 91-103.

5. Sierra M. Sueños un Camino al Despertar. $14^{\circ}$ edición. Editorial Persona Santiago, Chile 1998.

6. Vergara D. Encuentro con Lola Hoffmann. $1^{\circ}$ edición Catalonia. Santiago, 2003.

Correspondencia:

Dr. Enrique Escobar Miguel

E-mail: doctoreem@123.cl 